\title{
Insulin resistance syndrome in postmenopausal women with cardiological syndrome $\mathrm{X}$
}

Ian F Godsland, David Crook, John C Stevenson, Peter Collins, Giuseppe M C Rosano, Belinda Lees, Mandeep Sidhu, Philip A Poole-Wilson

\begin{abstract}
Objective-To determine whether postmenopausal women with cardiological syndrome $X$ (chest pain and abnormal exercise electrocardiogram despite normal coronary angiography) exhibit disturbances in the full range of proposed components of the putative "insulin resistance syndrome".
\end{abstract}

Patients and methods-20 postmenopausal women with syndrome $X$ and 20 healthy controls each underwent measurement of insulin resistance (by minimal model analysis of the intravenous glucose tolerance test), lipid, lipoprotein, and apolipoprotein concentrations, a range of haemostatic variables, serum uric acid concentration, and centrality of body fat distribution (by dual energy $x$ ray absorptiometry).

Results-Women with syndrome $X$ had higher fasting triglyceride concentrations than controls (median: $1.60 \quad v \quad 1.02$ $\mathrm{mmol} / \mathrm{h}, \mathrm{P}<0.05)$. Concentrations of high density lipoprotein cholesterol were lower $(1.33 v 1.61 \mathrm{mmol} / \mathrm{l}, P<0.05)$ as were those of the high density lipoprotein apolipoproteins AI and AII. Insulin and C peptide responses to the intravenous glucose tolerance test were higher $(27.6 v$ $19.8 \mu \mathrm{U} / \mathrm{ml} / \mathrm{min}, \quad P<0.01 ; \quad 101 \quad v \quad 72$ $\mathrm{pmol} / \mathrm{ml} / \mathrm{min}, \mathrm{P}<0.05$, respectively), and insulin sensitivity was lower (1.89 $v$ 3.09 $\mathrm{min} / \mu \mathrm{U} / \mathrm{ml}, \mathrm{P}<0.05)$. There were, however, no significant differences between other proposed components of the insulin resistance syndrome (blood pressure, glucose tolerance, proportion of central body fat, serum uric acid concentration, and plasminogen activator inhibitor-1 activity). Antithrombin III activity was higher in women with syndrome $X$ (121 $v$ $113 \%, P<0.01$ ).

Conclusions-Women with syndrome $\mathbf{X}$ tend to be insulin resistant and have lipid and lipoprotein abnormalities, but do not exhibit all characteristics of the insulin resistance syndrome. Such variation in correlated risk factors is consistent with underlying heterogeneity in the insulin resistance syndrome and cardiological syndrome $X$.

(Br Heart f 1995;74:47-52)

Keywords: insulin resistance, postmenopausal women, syndrome $\mathrm{X}$
The term "syndrome X" was introduced in 1973 by $\mathrm{Kemp}^{1}$ to acknowledge uncertainties over the aetiology of angina-like chest pain accompanied by angiographically normal coronary arteries. Conventional diagnostic criteria also include some further evidence of myocardial ischaemia, such as increased myocardial lactate production, reduced coronary sinus oxygen saturation, ST depression on exercise electrocardiogram, and impaired vasodilator reserve. ${ }^{2}$ Inconsistencies in the expression of these features, however, indicate a degree of heterogeneity in the condition. ${ }^{3}$

There is increasing evidence that cardiological syndrome $\mathrm{X}$ is accompanied by disturbances in metabolic risk factors for vascular disease, notably insulin resistance. ${ }^{45}$ Patients with syndrome $\mathrm{X}$ might therefore exhibit the putative "insulin resistance syndrome" (itself referred to as syndrome $\mathrm{X}$ or metabolic syndrome X). ${ }^{6}$ This syndrome has been invoked to account for reports of clustering among increased concentrations of insulin, glucose, and triglyceride, reduced concentrations of high density lipoprotein (HDL), and raised blood pressure. ${ }^{7}$ Experimental studies have provided evidence for biochemical and physiological links between insulin resistance and other risk factors for cardiovascular disease, thus supporting the hypothesis that insulin resistance is the abnormality that underlies this syndrome of metabolic disturbance. ${ }^{89}$

We have previously demonstrated these disturbances in men with syndrome $\mathrm{X},{ }^{10}$ but other studies have suggested less consistent metabolic characteristics. ${ }^{45}$ There is also uncertainty over the importance of impaired glucose tolerance as a component of the insulin resistance syndrome, and controversy over the extent to which changes in blood pressure are directly related to disturbances in insulin metabolism. ${ }^{11}$ Furthermore, new candidates for inclusion in the insulin resistance syndrome have been proposed, including increased concentrations of uric acid and increased activity of plasminogen activator inhibitor-1 (PAI-1). ${ }^{6} \mathrm{~A}$ central or android pattern of fat distribution may also be important. ${ }^{12}$ These variables have yet to be explored in detail in patients with cardiological syndrome $\mathrm{X}$, as have intercorrelations between candidate components of the insulin resistance syndrome. In particular, there is a lack of metabolic information concerning syndrome $\mathrm{X}$ in women. Women comprise the majority of sufferers from the condition ${ }^{13}$ and an involvement of the menopause is suggested by their relatively high mean age. ${ }^{14}$ 
In the present study, we undertook to determine whether insulin resistance syndrome was present in 20 postmenopausal women with syndrome $\mathrm{X}$ by comparing them with an age and weight matched group of healthy controls.

\section{Patients and methods}

PATIENTS

Women with syndrome $\mathrm{X}$ were recruited from a trial of transdermal oestrogen treatment. Inclusion in this trial required a history of anginal chest pain, a treadmill or bicycle exercise test with $>1 \mathrm{~mm}$ ST depression in any lead, and a coronary angiogram considered normal-that is, not showing more than $30 \%$ stenosis, by two experienced observers. Left ventricular hypertrophy, mitral valve defect, or any other structural abnormality as diagnosed by chest radiograph or echocardiogram constituted exclusion criteria, as did any existing electrocardiogram (ECG) abnormalities likely to interfere with interpretation of an ECG during treadmill exercise testing, for example, left bundle branch block. Women with blood pressure greater than or equal to $160 / 100 \mathrm{~mm} \mathrm{Hg}$ were also excluded. All recruits underwent evaluation for vasospastic angina (hyperventilation or ergonivine test) and all were negative. Four women had reversible perfusion defects on thalium scanning. Postmenopausal status (natural or surgical) was confirmed by amenorrhoea of at least 6 months duration, a follicle stimulating hormone level $>40 \mathrm{IU} / 1$, and an estradiol concentration $<100 \mathrm{pmol} / 1$. No hormone replacement treatment or cardiac medication (except glyceryl trinitrate as rescue medication) was allowed for 4 weeks before baseline studies. Of the 26 women who entered the trial, three were not white, two were grossly obese ( $>145 \%$ ideal body weight), and one had no insulin measurements during her intravenous glucose tolerance test (IVGTT). Studies carried out before treatment in the remaining 20 patients are evaluated in the present analysis.

Twenty healthy, non-hypertensive postmenopausal women attending a menopause clinic were selected to provide a control group of comparable age and weight to the patient group. Criteria for postmenopausal status were the same as for the women in the syndrome $\mathrm{X}$ group, but cigarette smokers were excluded. No drugs likely to affect carbohydrate or lipid metabolism were taken.

These studies were approved by the ethics committees of the Wynn Institute and the National Heart and Lung Institute and each participant gave written, informed consent.

\section{PROCEDURES}

All women were instructed to consume more than $200 \mathrm{~g} /$ day of carbohydrate for 3 days before their tests. Tests began between 0900 and 1000 after an overnight fast. Age, height, weight, time since menopause, and details of alcohol consumption, smoking, family history of diabetes and heart disease, and number of pregnancies were recorded. Exercise habit was defined as 'aerobic' for those women who undertook, at least three times a week for 20 min or more, exercise requiring a noticeable increase in breathing rate, 'non-aerobic' for those who described themselves as taking only moderate exercise, and 'none' for those who described themselves as taking no exercise. Time since menopause for women who had undergone a hysterectomy was taken as the time since onset of menopausal symptoms. Numbers of close relatives (parents or siblings) with heart disease or diabetes were recorded. Blood pressure was measured after patients had rested in a semirecumbent position for $15 \mathrm{~min}$. Indwelling cannulae were inserted into an antecubital vein in each arm, one for glucose administration and the other for sampling. Blood samples were taken for measurement of fasting plasma glucose, insulin, C peptide, serum lipid, and lipoprotein concentrations and factors of the coagulation and fibrinolytic systems. In two cases no samples were taken for coagulation and fibrinolytic assays due to technical problems. An additional sample was taken after $10 \mathrm{~min}$ for replicate measurement of fasting plasma glucose, insulin, and $\mathrm{C}$ peptide concentrations. An intravenous glucose injection $(0.5 \mathrm{~g}$ glucose $/ \mathrm{kg}$ body weight as a $50 \%$ (wt/vol) solution of dextrose) was given over $3 \mathrm{~min}$ and samples were taken at $3,5,7,10,15,20,30$, $45,60,75,90,120,150$, and $180 \mathrm{~min}$. Regional distribution of fat and lean tissue was measured by dual energy $x$ ray absorptiometry using a whole body scanner (DPX: Lunar Radiation, Madison, Wisconsin).

\section{LABORATORY PROCEDURES}

Plasma glucose was measured by a glucose oxidase technique. ${ }^{15}$ Plasma insulin and $C$ peptide were measured using double antibody radioimmunoassays (Guildhay, Guildford, UK). Serum triglycerides, total cholesterol, and uric acid were measured using enzymatic methods. HDL cholesterol was measured after heparin manganese precipitation of other lipoproteins ${ }^{16}$ and HDL subfractions after further precipitation with dextran sulphate. ${ }^{17}$ Very low density lipoprotein (VLDL) cholesterol and triglyceride were measured after preparative ultracentrifugation at a solvent density of $1.006 \mathrm{~g} / \mathrm{l}$, and low density lipoprotein (LDL) cholesterol was estimated as the difference between total cholesterol and the sum of HDL and VLDL cholesterol Apolipoproteins AI, AII, and B were measured by immunoturbidimetric assays, ${ }^{18}$ and $\mathrm{Lp}$ (a) lipoprotein by an enzyme linked immunosorbent assay (Biopool $\mathrm{AB}$, Umea, Sweden). Plasma fibrinogen, factors VIIa and $\mathrm{X}$, protein $\mathrm{C}$ and protein $\mathrm{S}$ were measured by nephelometric techniques on an automated coagulation analyser (ACL 100 Instrumentation Laboratory, Milan, Italy) Antithrombin III (AT III) and plasminogen were measured by enzymatic methods (Chromogenix, Mölndal, Sweden) on a discrete clinical analyser (Cobas Mira, Roche Diagnostics, Switzerland). Tissue plasminogen activator and PAI-1 were measured by 
Table 1 Group characteristics in women with syndrome $X$ and controls

\begin{tabular}{|c|c|c|}
\hline & $\begin{array}{l}\text { Women with } \\
\text { syndrome } X\end{array}$ & Controls \\
\hline n & 20 & 20 \\
\hline Age (years) & $58 \cdot 0(47-65)$ & $57 \cdot 0(46-65)$ \\
\hline Body mass index $\left(\mathrm{kg} / \mathrm{m}^{2}\right)$ & $26 \cdot 3(22 \cdot 4-30 \cdot 4)$ & $25 \cdot 6(22 \cdot 6-27 \cdot 7)$ \\
\hline Time since menopause (years) & $7 \cdot 5(0-35)$ & $6.5(0-26)$ \\
\hline No of patients who underwent hysterectomy $(\%)^{\star}$ & & \\
\hline Alcohol consumption (Units/week) & $2.0(0-21)$ & $3.5(0-21)$ \\
\hline \multicolumn{3}{|l|}{ Cigarette smokers (\%) } \\
\hline Never & 45 & 70 \\
\hline Previous & 35 & 30 \\
\hline Current & 20 & 0 \\
\hline \multicolumn{3}{|l|}{ No of patients taking exercise (\%) } \\
\hline None & 40 & 25 \\
\hline Non-aerobic & 50 & 35 \\
\hline Aerobict & 10 & 40 \\
\hline Family history of diabetes mellitus (\%)t & 25 & 5 \\
\hline Family history of heart disease (\%) & 60 & 50 \\
\hline \multicolumn{3}{|l|}{ No of pregnancies (\%) } \\
\hline $\begin{array}{l}\text { None } \\
1-2\end{array}$ & $\begin{array}{l}20 \\
55\end{array}$ & $\begin{array}{l}20 \\
30\end{array}$ \\
\hline$>2$ & 25 & 50 \\
\hline
\end{tabular}

Values are median (range) unless otherwise specified. ${ }^{\star}$ The greater proportion of women with syndrome $X$ who had a hysterectomy was of borderline significance $(P=0.08)$. †Proportions of syndrome $X$ who had a hysterectomy was of borderline significance $(P=0.08)$. †Proportions of
current cigarette smokers and women with a family history of diabetes were significantly higher in the syndrome $X$ group, and the proportion of women taking aerobic exercise significantly lowe $(P<0.05)$ (Mann-Whitney U test)

manual enzymatic methods (Chromogenix) and fibrinopeptide $\mathrm{A}$ by radioimmunoassay (Byk-Sangtec, Dietzenbach, Germany).

\section{DATA ANALYSIS}

Android fat was estimated by dual energy $x$ ray absorptiometry as the sum of fat mass in predefined waist and subscapular areas, and gynoid fat as the sum of hip and thigh fat. ${ }^{19}$ The ratio of fat in the android relative to the gynoid region was calculated, and proportions of android and gynoid fat were expressed as percentages of total body fat. Mean fasting plasma glucose, insulin and $\mathrm{C}$ peptide concentrations were derived from the two basal measurements. Incremental glucose, insulin, and $C$ peptide areas (the area between the fasting level and the IVGTT concentration profile) were calculated by the trapezium rule. Insulin sensitivity $\left(S_{i}\right)$ and glucose effectiveness were determined by minimal model analysis of the IVGTT glucose and insulin concentration profiles. ${ }^{20}$ The relatively high glucose dose $(0.5 \mathrm{~g} / \mathrm{kg})$ employed in the present studies allows for effective model identification, ${ }^{21}$ and insulin sensitivity estimates that

Table 2 Fasting serum lipid, lipoprotein and apolipoprotein concentrations in women with syndrome $X$ and controls

\begin{tabular}{|c|c|c|}
\hline & Women with syndrome $X$ & Controls \\
\hline $\mathbf{n}$ & 20 & 20 \\
\hline Triglycerides $(\mathrm{mmol} / \mathrm{l})$ & $1.60(0.68-4.60)$ & $1.02(0.57-3.50)^{\star}$ \\
\hline Total cholesterol $(\mathrm{mmol} / \mathrm{l})$ & $5.99(4.52-8.58)$ & $5 \cdot 76(4 \cdot 37-7 \cdot 51)$ \\
\hline LDL cholesterol (mmol/l) & $4 \cdot 35(2 \cdot 70-6 \cdot 46)$ & $3 \cdot 76(2 \cdot 76-5 \cdot 48)$ \\
\hline HDL cholesterol (mmol/i) & $1.33(0.85-2.55)$ & $1.61(0.88-2.94)^{\star}$ \\
\hline $\mathrm{HDL}_{2}$ cholesterol $(\mathrm{mmol} / \mathrm{i})$ & $0.40(0.07-1.40)$ & $0.49(0 \cdot 10-1.69)$ \\
\hline $\mathrm{HDL}_{3}$ cholesterol $(\mathrm{mmol} / \mathrm{l})$ & $0.94(0.68-1.25)$ & $1.06(0.78-1.33)$ \\
\hline VLDL cholesterol (mmolí) & $0.43(0.08-1.71)$ & $0.20(0.08-1.62)$ \\
\hline VLDL triglyceride $(\mathrm{mmol} / \mathrm{l})$ & $0.53(0.17-3.24)$ & $0.39(0.15-2 \cdot 23)$ \\
\hline VLDL cholesterol/triglyceride molar ratio & $0.52(0.32-0.81)$ & $0.57(0.40-0.87)$ \\
\hline Apolipoprotein AI (mg/dl) & $132(97-200)$ & $149(110-196)^{\star}$ \\
\hline Apolipoprotein AII (mg/dl) & $38(29-52)$ & $43(36-55)^{\star}$ \\
\hline Apolipoprotein B (mg/d̆) & $74(48-108)$ & $73(43-98)$ \\
\hline Lp(a) lipoprotein (mg/dl) & $8.9(0-85)$ & $7 \cdot 6(0-55)$ \\
\hline
\end{tabular}

Values are median (range). ${ }^{\star} \mathrm{P}<0.05 v$ women with syndrome $\mathrm{X}$ (Mann-Whitney $\mathrm{U}$ test) LDL, low density lipoprotein; HDL, high density lipoprotein; VLDL, very low density lipoprotein. correlate well with those derived from the glycaemic clamp $(r=0.92) .{ }^{22}$ Insulin delivery characteristics were evaluated using the minimal model of post-hepatic insulin delivery, which provides measures of fractional insulin elimination rate (inversely related to the plasma insulin half-life), and measures of the responsiveness of first and second phase insulin delivery to glucose $\left(\varphi_{1}\right.$ and $\varphi_{2}$ respectively). A combined model of insulin and $C$ peptide delivery ${ }^{23}{ }^{24}$ was used to quantify the fractional insulin elimination rate, a measure of the fraction of newly secreted insulin that passes out of the liver, and incremental pancreatic insulin secretion during the IVGTT. Models describing insulin delivery have been evaluated previously..$^{2123}$

Differences between the groups were assessed by the Mann-Whitney $U$ test. Relations between individual components of the insulin resistance syndrome were explored using Spearman's correlation. Statistical analyses employed BMDP statistical software (Los Angeles, California).

\section{Results}

The two groups did not differ significantly in age, body mass index, time since menopause or alcohol consumption, nor in the percentage of women with a family history of heart disease or in the number of pregnancies (table 1). Four women with syndrome $X$ were current smokers compared with none in the control group. The percentages of women who had undergone hysterectomy and who had a family history of diabetes were higher in patients with syndrome $\mathrm{X}$ and the proportion of women who took aerobic exercise was lower.

There were no significant differences between women with syndrome $\mathrm{X}$ and controls in android to gynoid fat ratio (median: $0.91 v 0.90$, respectively), percentage of android fat $(32.0 v 32 \cdot 6)$, percentage of gynoid fat (35.5 $v 34.5)$, diastolic or systolic blood pressure $(70 v 72$ and $130 v 120 \mathrm{~mm}$ $\mathrm{Hg}$ ), or serum uric acid concentrations $(220 v$ $218 \mu \mathrm{mol} / \mathrm{l}$ ). Serum triglycerides were $57 \%$ higher in patients with syndrome $\mathrm{X}$ than in the controls and VLDL cholesterol and triglyceride were appropriately increased (table 2). HDL cholesterol was $17 \%$ lower, and apolipoprotein AI and apolipoprotein AII were $11 \%$ lower than in the control group. The lower HDL cholesterol levels were reflected in lower values for $\mathrm{HDL}_{2}$ and $\mathrm{HDL}_{3}$ cholesterol. Women with syndrome $\mathrm{X}$ had normal concentrations of total and LDL cholesterol, apolipoprotein $\mathrm{B}$, and $\mathrm{Lp}$ (a) lipoprotein.

There were no differences between women with syndrome $\mathrm{X}$ and controls in fasting plasma concentrations of glucose (median: $5.29 v 5.10 \mathrm{mmol} / 1$, respectively), insulin $(0.065 v 0.065 \mathrm{pmol} / \mathrm{ml})$ or C peptide $(0.44 v$ $0.39 \mathrm{pmol} / \mathrm{ml}$ ). Insulin and $C$ peptide areas of the IVGTT were respectively $39 \%$ and $40 \%$ higher in patients with syndrome $\mathrm{X}$ than in controls and $S_{i}$ was $39 \%$ lower (table 3 ). The 
Table 3 Glucose, insulin, and $C$ peptide responses to the intravenous glucose tolerance test (IVGTT) and model derived variables in women with syndrome $X$ and controls

\begin{tabular}{|c|c|c|}
\hline & Women with syndrome $X$ & Controls \\
\hline $\mathbf{n}$ & 20 & 20 \\
\hline \multicolumn{3}{|l|}{ IVGTT incremental areas } \\
\hline Glucose $\left(\mathrm{mmol} .1^{-1} \cdot \mathrm{min}\right)$ & $528(334-871)$ & $550(205-853)$ \\
\hline Insulin (pmol.ml $\left.{ }^{-1} \cdot \mathrm{min}\right)$ & $27 \cdot 6(13 \cdot 1-42 \cdot 4)$ & $19 \cdot 8(6 \cdot 0-82 \cdot 2)+$ \\
\hline C peptide (pmol.ml-1.min) & $101(50-190)$ & $72(35-201)^{\star}$ \\
\hline \multicolumn{3}{|l|}{ Minimal model of glucose disappearance } \\
\hline $\mathrm{Sg}\left(\min ^{-1}\right)$ & $1 \cdot 70(0 \cdot 10-3 \cdot 22)$ & $1.46(0.50-6.05)$ \\
\hline $\mathrm{S}_{\mathrm{i}}\left(\min ^{-1} \cdot \mu \mathrm{U}^{-1} \cdot \mathrm{ml}\right)$ & $1.89(0.06-9.15)$ & $3.09(0.68-7.91)^{\star}$ \\
\hline \multicolumn{3}{|l|}{ Post-hepatic insulin delivery model } \\
\hline $\begin{array}{l}\mathrm{n}_{\mathrm{i}}\left(\mathrm{min}^{-1}\right) \\
\emptyset_{1}\left(\mu \mathrm{U} \cdot \mathrm{ml}^{-1} \cdot \mathrm{min} \cdot \mathrm{mg}^{-1} \cdot \mathrm{ml}\right) \\
\emptyset_{2}\left(\mu \mathrm{U} \cdot \mathrm{ml}^{-1} \cdot \mathrm{min}^{-2} \cdot \mathrm{mg}^{-1} \cdot \mathrm{ml}\right)\end{array}$ & $\begin{array}{l}0.144(0.040-0.257) \\
4.64(1 \cdot 28-13.78) \\
10.9(3.9-45 \cdot 2)\end{array}$ & $\begin{array}{l}0 \cdot 151(0.022-0 \cdot 240) \\
3 \cdot 36(1 \cdot 99-21 \cdot 14) \\
9 \cdot 2(0 \cdot 9-18 \cdot 8)\end{array}$ \\
\hline \multicolumn{3}{|l|}{ Pancreatic insulin secretion model } \\
\hline F & $0.98(0.42-2 \cdot 19)$ & $0.94(0.54-1.69)$ \\
\hline $\mathrm{k}_{i}\left(\min ^{-1}\right)$ & $0.080(0.035-0.240)$ & $0.110(0.016-0.169)$ \\
\hline $\mathrm{IS}_{\mathrm{inc}}\left(\mathrm{pmol} \cdot \mathrm{ml}^{-1} \cdot \mathrm{min}\right)$ & $2 \cdot 25(1 \cdot 36-4 \cdot 84)$ & $1.67(0.21-6.45)$ \\
\hline
\end{tabular}

Values are median (range). ${ }^{\star} \mathrm{P}<0.05 ;+\mathrm{P}<0.01$ (Mann-Whitney $U$ test). $S_{\mathrm{g}}$, glucose effectiveness; $S_{i}$, insulin sensitivity; $n_{i}$, fractional insulin elimination rate (post-hepatic insulin delivery model); $\phi_{1}$, first phase insulin delivery to glucose; $\emptyset_{2}$, second phase insulin delivery to glucose; $F$, model); $\phi_{1}$, first phase insulin delivery to glucose; $\emptyset_{2}$, second phase insulin delivery to glucose; F,
fractional hepatic insulin throughput index; $\mathrm{IS}_{\text {inc }}$, net increment in pancreatic insulin secretion

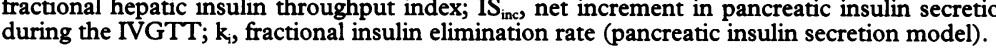

Table 4 Factors of the coagulation and fibrinolytic systems in women with syndrome $X$ and controls

\begin{tabular}{lcc}
\hline & Women with syndrome $X$ & Controls \\
\hline $\mathrm{n}$ & 18 & 20 \\
Fibrinogen (mg/dl) & $338(236-417)$ & $347(222-518)$ \\
Factor VII (\%) & $120(82-169)$ & $126(82-156)$ \\
Factor X (\%) & $119(76-142)$ & $112(94-143)$ \\
Protein C (\%) & $124(98-148)$ & $124(71-169)$ \\
Protein S (\%) & $118(63-165)$ & $104(65-196)$ \\
Antithrombin III (\%) & $121(103-130)$ & $113(97-134)^{\star}$ \\
Plasminogen (\%) & $108(90-130)$ & $114(85-136)$ \\
Plasminogen activator inhibitor-1 (AU/ml) & $8 \cdot 2(1 \cdot 0-38 \cdot 2)$ & $5 \cdot 2(1 \cdot 0-29 \cdot 2)$ \\
Tissue plasminogen activator (IU/ml) & $1 \cdot 35(0 \cdot 20-4 \cdot 80)$ & $1 \cdot 05(0 \cdot 30-2 \cdot 60)$ \\
Fibrinopeptide A (ng/ml) & $9 \cdot 7(3 \cdot 7-79 \cdot 6)$ & $14 \cdot 0(3 \cdot 1-89 \cdot 0)$ \\
\hline
\end{tabular}

Values are median (range). ${ }^{\star} \mathrm{P}<0.01$ (Mann-Whitney $U$ test).

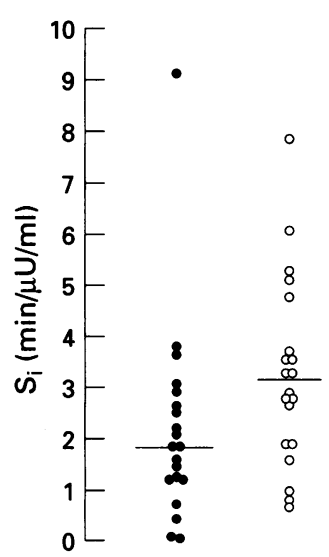

Insulin sensitivity $\left(S_{i}\right)$ in postmenopausal women with cardiological syndrome $X(\bullet)(n=20)$ and in age and weight matched healthy controls () $(n=20)$. The median value is indicated by the horizontal line in each plot. with syndrome $X$ and controls $(n=40)$ controls (table 4), otherwise there were no significant differences between coagulation and fibrinolytic factors.

Repeating these comparisons in analyses in which current smokers $(n=4)$, women who had undergone hysterectomy $(n=11)$, or those with a family history of diabetes $(n=6)$. were excluded did not affect the significance of the differences seen. Exclusion of those taking aerobic exercise $(n=10)$ reduced some significance levels, but in each of these comparisons the magnitude of the difference between the groups remained the same. For example, median $S_{i}$ was between 36 and $44 \%$ lower, triglycerides between 48 and $75 \%$ higher, and HDL cholesterol between 13 and $24 \%$ lower in the remaining women with syndrome X.

Correlations between potential components of the insulin resistance syndrome were examined in the syndrome $\mathrm{X}$ and control groups separately. The magnitude of the correlations in each group were generally similar (results not shown), therefore these relations were evaluated in the study group as a whole. There were significant associations among percentage of android fat, serum triglyceride and HDL cholesterol concentrations, and insulin response to the IVGTT (table 5). $S_{\mathrm{i}}$ also correlated significantly with triglycerides of and HDL, although the association with proportion of android fat was of borderline significance $(r=-0.29, \mathrm{P}=0.06)$. PAI-1 concentrations decreased with increasing $S_{i}$ and HDL cholesterol concentration and rose with increasing percentage of android fat $(r=$ $0.31, P=0.05)$. The only significant correlate of serum uric acid concentration was PAI-1 activity. Systolic blood pressure correlated with IVGTT insulin response, but only with borderline significance $(r=0.32, \mathbf{P}=0.07)$. Otherwise there were no associations between blood pressure and components of the insulin resistance syndrome. Interrelationships between $S_{i}$ and several other variables were examined. There was a negative association between $S_{i}$ and time since menopause $(r=$ $0.37, P<0.05$ ) while no such association was seen with chronological age $(r=0 \cdot 15, \mathrm{P}>$ $0 \cdot 3)$. AT III levels correlated with insulin response to the IVGTT $(r=0.40, \mathrm{P}<0.01)$ and $S_{i}(r=0.31, P=0.06)$ and decreasing $S_{i}$ was associated with increasing activity of factor $\mathrm{X} .(r=-0.33, \mathrm{P}<0.05)$.

Table 5 Univariate correlation coefficients (Spearman) among components of the insulin resistance syndrome for women

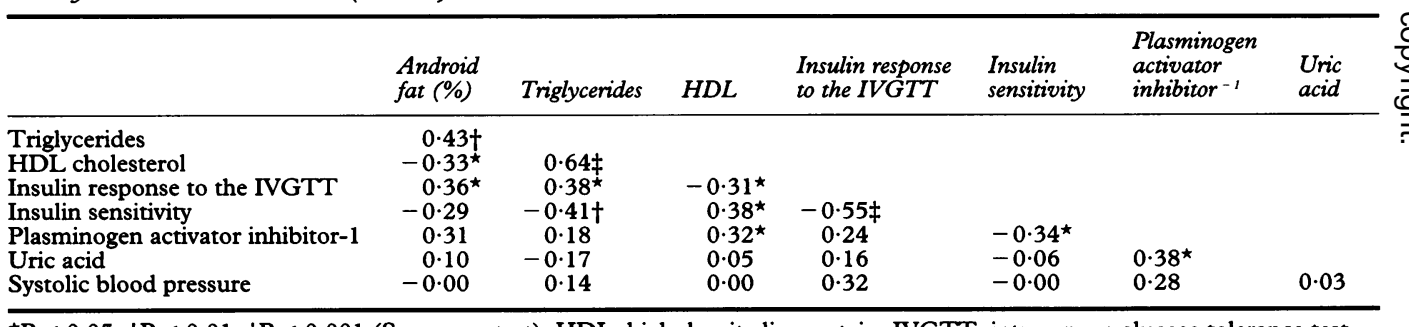

${ }^{\star} \mathrm{P}<0.05 ;+\mathrm{P}<0.01 ; \ddagger \mathrm{P}<0.001$ (Spearman test). HDL, high density lipoprotein; IVGTT, intravenous glucose tolerance test. 


\section{Discussion}

This study shows that postmenopausal women with syndrome $\mathrm{X}$ tend to have insulin resistance, hyperinsulinaemia, increased triglyceride concentrations, and reduced HDL cholesterol concentrations compared with those of healthy postmenopausal women. The two groups were of comparable age and body mass index, although there were differences in other characteristics. An increased incidence of hysterectomy has previously been found in women with syndrome $\mathrm{X}^{14}$ and the fewer women taking aerobic exercise is to be expected. Cigarette smoking was an exclusion criterion for the studies from which the control group was drawn, so no inferences can be made regarding the difference in smoking habit between the two groups. The difference in family history of diabetes is unexpected and may be worth examining in larger samples. Nevertheless, in subgroup analyses it was apparent that the metabolic differences between the groups were present regardless of these differences in group characteristics.

While three of the characteristics of the insulin resistance syndrome, insulin resistance, high triglycerides, and low HDL cholesterol, were present in the cardiological syndrome $\mathrm{X}$ group, blood pressure, glucose tolerance, PAI-1 activity, uric acid concentration, and body fat distribution did not differ from those of healthy controls. We have previously observed similarly reduced $S_{i}$, increased triglycerides, and reduced HDL cholesterol in men with syndrome $\mathrm{X}$, but in that study the patients had significantly higher systolic blood pressure. ${ }^{10}$ Other studies have examined mixed groups of men and women. Where measured, $S_{i}$ in those with syndrome $X$ was also about $40 \%$ lower than in healthy controls. ${ }^{56}$ Glucose tolerance test studies have, with one exception, ${ }^{27}$ been consistent with this finding. ${ }^{28}$ Most studies show increased triglycerides and reduced HDL cholesterol, although these differences are generally less profound than the differences in insulin related variables. Where reported, most studies also show little difference in body fat distribution or blood pressure. Small numbers in some of the studies described might underlie the inconsistent differences in lipid and lipoprotein concentrations reported, but the consistent lack of a difference in blood pressure suggests that insulin resistance and raised blood pressure may not be linked in this condition.

Intercorrelations between components of the insulin resistance syndrome have not been explored in previous studies of cardiological syndrome $\mathrm{X}$. We found significant associations between insulin resistance, increased triglycerides, reduced HDL cholesterol, and proportion of android fat. The inclusion of android fat in this cluster is noteworthy as women with syndrome $\mathrm{X}$ did not have an increased proportion of android fat, suggesting that while android fat is an important correlate of metabolic disturbance it is not a factor in the differences seen between healthy postmenopausal women and those with syn- drome X. Increased PAI-1 activity was associated with low HDL cholesterol, low $S_{i}$ and an increased proportion of android fat, as would be expected for a component of the insulin resistance syndrome. There were no associations, however, between PAI-1 and triglycerides or the insulin response to the IVGTT. PAI-1 activity was higher in women with syndrome $\mathrm{X}$, but this was not statistically significant: possibly larger group sizes would have rendered this difference significant. Other factors of the coagulation and fibrinolytic systems have not previously been reported in women with syndrome $\mathrm{X}$. The importance of the raised AT III activities in women with syndrome $\mathrm{X}$ is difficult to assess: there seems to be a biphasic association between AT III activities and vascular disease, low and high activities being associated with increased risk, ${ }^{29}$ but there are no reports of increased thrombotic tendency in patients with cardiological syndrome $\mathrm{X}$. The positive associations among AT III, insulin resistance, and increased insulin levels suggest that increased AT III activities might be a candidate for the insulin resistance syndrome. Despite finding no significant differences in the activity of factor $\mathrm{X}$ between patients with syndrome $\mathrm{X}$ and controls, we found a positive association between $S_{i}$ and factor $\mathrm{X}$ activity. We are not aware of any previous reports linking insulin resistance with increased AT III or factor X activities.

A heterogeneous manifestation of disturbances therefore seems to be associated with the insulin resistance syndrome among the women who we studied, with a core of correlations among $S_{i}$, triglycerides, and HDL cholesterol, probable involvement of android fat levels and PAI-1 activities, and no involvement of uric acid or blood pressure. Whether these differences and associations are sufficient for us to conclude that women with cardiological syndrome $\mathrm{X}$ manifest the insulin resistance syndrome is arguable. This uncertainty is emphasised by the considerable overlap in individual values between the groups, even in those components of the insulin resistance syndrome that differed significantly. A serious shortcoming in many discussions of the insulin resistance syndrome has been a lack of diagnostic criteria: while correlations and differences in median values may be highly suggestive with regard to groups as a whole, they are insufficient to confer a diagnosis on an individual. Differentials between insulin resistance as it relates to the glucoregulatory, antilipolytic, and haemodynamic effects of insulin may yet undermine the central position ascribed to insulin resistance in the aetiology of correlated metabolic disturbances. Furthermore, it is becoming increasingly apparent that insulin resistance can itself be induced by many of the disturbances that are typical of the syndrome, making it difficult to justify a strict causal chain from insulin resistance to its various manifestations. ${ }^{9}$

In general, the prognosis of patients with cardiological syndrome $\mathrm{X}$ is good, ${ }^{314}$ calling into question a role for insulin resistance in 
the aetiology of coronary artery disease. Follow up studies of patients with syndrome $\mathrm{X}$ may have included a substantial proportion who were not insulin resistant. Alternatively, the long-term effects of insulin resistance associated with vascular dysfunction may differ from those of insulin resistance associated with more general, atherogenic metabolic derangement; moreover, a certain minimum complement of metabolic disturbances associated with insulin resistance may be needed to influence long-term health. To resolve these issues, future studies will need to pay particular attention to potential heterogeneity in the insulin resistance syndrome and cardiological syndrome $\mathrm{X}$.

We thank Dr Philip Sarrel for his help in initiating these studies, Drs David Lindsay, Nicholas Peters, David Lefroy, Michael Marsh, and Sovra Whitcroft for clinical support, Anthony Proudler, Dr Carl Felton, Melek Worthington, and Maire Cullinan for technical assistance, and Mary Miller and Lee Mayne for nursing assistance. Financial support for this study was provided by Ciba-Geigy Pharmaceuticals, Novo Nordisk Pharmaceuticals, the Heart Disease and Diabetes Research Trust, and the Rosen Foundation.

1 Kemp HG. Left ventricular function in patients with the anginal syndrome and normal coronary arteriograms. Am $\mathcal{F}$ Cardiol 1973;32:375-6.

2 Hutchinson SJ, Poole-Wilson PA, Henderson AH. Angina with normal coronary arteries: a review. $Q \mathcal{F} M e d 1988$ 72:677-88.

3 Cannon III RO, Camici PG, Epstein SE. Pathophysiological dilemma of syndrome X. Circulation 1992;85: 883-92.

4 Dean JD, Jones CJH, Hutchinson SJ, Peters JR, Henderson AH. Hyperinsulinaemia and microvascular angina ("syndrome X"). Lancet 1991;337:456-7.

5 Bøtker HE, Møller N, Ovesen P, Mengel A, Schmitz O, Ørskov $\mathrm{H}$, et al. Insulin resistance in microvascular angina (syndrome X). Lancet 1993;342:136-40.

6 Reaven GM. Role of insulin resistance in human disease (syndrome X): an expanded definition. Annu Rev Med 1993;44:121-31.

7 Moller D, Flier J. Insulin resistance-mechanisms, syndromes, and implications. N Engl f Med 1991;325: 938-48.

8 Reaven G. Banting lecture 1988: role of insulin resistance in human disease. Diabetes 1988;37:1595-607.

9 Frayn K. Insulin resistance and lipid metabolism. Current Opinion in Lipidology 1993;4:197-204.
10 Swan JW, Walton C, Godsland IF, Crook D, Oliver MF, Stevenson JC. Insulin resistance syndrome as a feature of cardiological syndrome $\mathrm{X}$ in non-obese men. Br Heart f 1994;71:41-4.

11 Jarrett RJ. In defence of insulin: a critique of syndrome $\mathrm{X}$. Lancet 1992;340:469-71.

12 Björntorp P. Metabolic implications of body fat distribution. Diabetes Care 1991;14:1132-43.

13 Wenger N, Speroff L, Packard B. Cardiovascular health and disease in women. $N$ Engl f Med 1993;329:247-56.

14 Rosano GMC, Kaski JC, Collins P, Maseri A, PooleWilson PA. Clinical features and long-term follow-up of $T$ 99 consecutive patients with syndrome $\mathrm{X}$. [abstract] $\mathcal{F}$ Am Coll Cardiol 1993;21:475.

15 Trinder P. Determination of blood glucose using an oxi- $c$ dase-peroxidase system with non-carcinogenic chromogen. $\mathcal{F}$ Clin Pathol 1969;22:158-61.

16 Warnick GR, Albers JJ. A comprehensive evaluation of the heparin-manganese precipitation procedure for $\overline{0}$ estimating high density lipoprotein cholesterol. F Lipid $\bar{O}$ Res 1978;19:65-76.

17 Gidez LI, Miller GJ, Burnstein M, Slagle S, Eder HA. Separation and quantitation of subclasses of human plasma high density lipoproteins by a simple precipitation procedure. $F$ Lipid Res 1982;23:1206-23.

18 Mount IN, Kearney EM, Rosseneu M, Slavin BM. क Immunoturbidimetric assays for serum apoproteins $A 1 \vec{O}$ and B using Cobas Bio centrifugal analyser. $\mathcal{F}$ Clin Pathol 1988;41:471-4.

19 Ley C, Lees B, Stevenson J. Sex- and menopause-associated changes in body fat distribution. Am 7 Clin Nutr 1992;55:950-4

20 Bergman RN, Ider YZ, Bowden CR, Cobelli C. Quantitative estimation of insulin sensitivity. $A m$ f Physiol 1979;236:E667-77.

21 Walton C, Godsland IF, Proudler AJ, Felton C, Wynn V. Aे Evaluation of four mathematical models of glucose and insulin dynamics with analysis of the effects of age and 음 obesity. Am 7 Physiol 1992;262:E755-62.

22 Swan J, Walton C, Godsland IF. Assessment of insulin sensitivity in man: a comparison of minimal model and euglycaemic clamp derived measures in health and heart euglycaemic clamp derived meas

23 Volund A, Polonsky K, Bergman R. Calculated pattern of $\vec{\varphi}$ intraportal insulin appearance without independent of assessment of C-peptide kinetics. Diabetes 1987;36: 1195-202.

24 Watanabe R, Vølund A, Roy S, Bergman R. Prehepatic beta-cell secretion during the intravenous glucose tolerance test in humans: application of a combined model of insulin and C-peptide kinetics. $\mathcal{F}$ Clin Endocrinol Metab 1989;69:790-7.

25 Godsland I, Felton C, Proudler A, Wynn V. Evaluation of two methods for estimating pancreatic insulin secretion $\overrightarrow{\vec{\sigma}}$ by modelling analysis of the intravenous glucose toler- $\overline{\bar{O}}$ by modelling analysis of the intravenous glucose toler-

26 Fuh MM-T, Jeng C-Y, Young MM-S, Sheu WH-H, Chen Y-DI, Reaven GM. Insulin resistance, glucose intolerance and hyperinsulinaemia in patients with microvascular angina. Metabolism 1993;42:1090-2.

27 Saeed BT, Bartlett WA, Murray RG, Jones AF, Neattie $\overrightarrow{\mathbb{D}}$ $\mathrm{JM}$. Insulin resistance in syndrome $\mathrm{X}$ [letter]. Lancet 1993;342:555.

28 Chauhan A, Camici MC, Schofield PM. Insulin resistance in syndrome X [letter]. Lancet 1993;342:554

29 Meade TW, Cooper J, Miller GJ, Howarth DJ, Stirling Y. Antithrombin III and arterial disease. Lancet 1991;338: 850-1. 